\title{
Article
}

\section{Phosphate solubilization potential of native rhizospheric microflora and their impact on growth of Madhuca latifolia (Mahua): An oil yielding medicinal plant of India}

\author{
Mishra S, Pany S, Gupta N*
}

Plant Pathology and Microbiology Division Regional Plant Resource Centre, Bhubaneswar, Odisha 751015 India

Mishra S, Pany S, Gupta N 2018 - Phosphate solubilization potential of native rhizospheric microflora and their impact on growth of Madhuca latifolia (Mahua): An oil yielding medicinal plant of India. Studies in Fungi 3(1), 59-72, Doi 10.5943/sif/3/1/8

\begin{abstract}
Madhuca latifolia is an economically important medicinal and oil yielding plant of India having slow growth rate. As microbial application to the rhizosphere of host plant are beneficial for growth and development of plants, a comprehensive experimental study by using native microflora of Madhuca latifolia had been carried out in the nursery conditions. Isolation and identification of native rhizospheric soil revealed the occurrence of 17 different types of bacteria (gram negative and positive) and 30 numbers of fungi belonging to myceloid type, Aspergillus, Alternaria, Colletotrichum, Fusarium and Penicillium. Present study was confined to phosphate solubilizing microbes for which solubilization potential (solubilization index and solubilization efficiency) was evaluated. Inoculation experiments in pot culture with red laterite soil were set in two experimental categories (1) non-transplanted and (2) transplanted. Plants grown under both the conditions with and without microbial application were maintained up to 120 days and final data recorded for morphological, physiological growth and as soil parameters. The mineral solubilizing potential of native microbial strains has been expressed. Fungal inoculants were more effective than the bacterial inoculants as far as the growth and development of plants concerned. Among all, bacteria MLB-1, MLB-6, Aspergillus terreus and non-sporulating dematiaceous form of fungi were prominent in improving plant growth. This has also been confirmed the useful and beneficial impact of indigenous organism. The records made during the study is useful for development of bioinoculants for forest trees, nursery of quality planting material which will also helps in establishment at plantation site.
\end{abstract}

Key words - Bacteria - bioinoculants - forest trees - fungi - Madhuca latifolia - phosphate solubilization

\section{Introduction}

Microbial influences on environment and ourselves are well established facts and reflected in many ways. Their ubiquitous nature, beneficial and detrimental impact are exhibited everywhere and routinely. They are diversified as causal agent of many disease of human, plants and animals, on the other hand they are producers of useful and beneficial products. They play a pivot role in biological recycling. Resultantly, organic matter from plants, animals and other soil biota use to be recycled and extended indirect benefits to the host or surroundings. To this context, mineral 
solubilizing microbial strains are considered important, which can release soluble form of organic and inorganic content of minerals through various process like acidification, chelation and enzymatic process (Sharma et al. 2013). Phosphorous is an important element and required frequently at different stages of plant growth. It is also important for many cellular and functional organizations. However, it is available in least amount in the soil and indirectly restricts the growth of plants. Hence, Phosphorous supply through biological means is good alternative in this regard. It also helps in scavenging bound phosphorus and makes it available to the host plants. In this context, the use of rhizospheric microbes which are capable of mobilizing the phosphorous in available form is imperative. Many bacteria and fungi are reported as potential candidate as bioinoculants for the better growth and development of several agricultural, horticultural crops and forestry plantation (Bhardwaj et al. 2014). However, the capacity and quality of bioinoculants depend upon the source for this obtained, soil in which they are being inoculated and plant for which they are being applied. Hence, indigenous or native microflora may function in better way as far as inoculation of beneficial organism is concerned. With this opinion present study had been planned with objective to develop bioinoculants by using native microflora of Madhuca latifolia which is an important economic plant of dry and sub-tropical climate of central and southern India. It is a deciduous species and significant food source for liquor production. Besides food value, this is also known for its medicinal values and bio-diesel properties (Puhan et al. 2005). Though gregarious nature and good germination ability, it has stunt growth rate which affect the growers for their economic commercials. Application of useful beneficial microbes especially phosphate solubilization may be useful towards their growth promoting strategies.

\section{Materials \& Methods}

\section{Isolation of Native Microflora, Identification and Characterization}

Soil samples from the native plantation of Madhuca latifolia was collected by digging 10 inches from soil upper layer of the stem/root interface of Madhuca latifolia grows in Botanical Garden of the centre, soil samples were pooled and brought in polyethylene bags in the laboratory for analysis. Serial dilution and direct inoculation method was followed for the isolation of bacteria and fungi from the collected soil on Sabouraud and Nutrient agar media. Scattered colony formed which were separated purified and maintained for the further analysis. Plate culture morphology and slide culture technique were followed for the characterization and identification of fungal cultures. Bacterial cultures were identified (Barnett \& Hunter 1972, Zhu et al. 2011, Nagamani et al. 2013) for the Gram staining properties and segregated accordingly. All bacterial and fungal isolates were evaluated for their beneficial extracellular activity like phosphate solubilization. To do this individual organism were inoculated on specified media plates and after growth, tested accordingly.

\section{Analysis of Phosphate Solubilizing Efficiency}

All microbial isolates were screened on Pikovaskya's plates for their solubilizing activity in vitro condition (Karpagam \& Nagalahskmi 2014). The halozone forming cultures were selected further for their Phosphate content solubilization under submerged culture condition by following Vandomolybdate method yellow colour method (Tandon 1999). Solubilization efficiency and solubilization index were calculated as per the formula referenced by Elias et al. (2016).

\section{Inoculation Studies and Pot Experiments}

Pot experiment was carried out in Poly bags of size $12 \times 16 \mathrm{~cm}$ contained red laterite soil at $35 \pm 2{ }^{\circ} \mathrm{C}$ temperature with 60 to $80 \%$ humidity. The soil was loamy, sandy and having high content of iron, copper and manganese. Soil was analyzed for physicochemical properties (Wyszkowska et al. 2013) and used for experiments after fumigation with $1 \%$ Formalin $(20 \mathrm{ml} / \mathrm{bag})$ twice for 48 hours. The seeds were brownish in colour and soaked in dilute $\mathrm{HCl}(0.1 \mathrm{~N} \mathrm{HCl})$ overnight at room temperature and sown in poly bags pots. Single seedling was retained in each poly bag. Plants of 14 
days old were used for inoculation studies. The experiments were set in two sets of transplanted and non-transplanted for fungal and bacterial inoculants separately. $2.5 \mathrm{ml}$ of 7 days old culture (liquid submerged culture) prepared in Sabouraud and Nutrient agar medium of $\mathrm{pH} 5.8$ and 6, respectively and added to each pot containing single seedling of Madhuca latifolia of 14 days old age. This supplementation of bacterial and fungal culture was done thrice with monthly interval and data was recorded for morphological analysis. Similarly, bacterial culture of 72 hours old where supplemented to the individual pot $(25 \mathrm{ml} / \mathrm{pot})$ and repeated at monthly intervals for 120 days.

\section{Results}

\section{Native Microflora of Madhuca latifolia:}

Rhizospheric soil of Madhuca latifolia was analyzed for the incidence of fungi and bacteria. In all, 30 different fungi and 17 types of bacteria were found to be present in the rhizospheric soil. These isolates were further screened for phosphate solubilizing properties and the positive strains were studied for their morphological features in case of fungi and staining properties, biochemical and physiological properties of bacterial isolates in order to identify them. In the present study, the fungi were identified as non-sporulating dematiaceous form, Alternaria raphani J.W. Groves \& Skolko, Asperigillus flavus Link, Aspergillus nidulans (Eidam) G. Winla, Aspergillus niger gr., Aspergillus terreus Thom., Colletotrichum gloeosporioides (Penz.) Penz. \& Sacc. and Penicillium chermesinum Biourge. The bacterial isolates were categorized into gram positive and gram negative. Biochemical and physiological analysis exhibited variation among the gram positive and gram negative bacteria. Bacterial isolates 5, 7, 14 and 17 were positive towards Phenylalanine deamination tests and Lysine. The Bacterial isolates 12 and 16 were positive towards Nitrate reductase and Arginine. Bacterial isolate 6 could be able to ferment Esculine, Glucose, Rhamnose along with Phenylalanine deamination activity. Differences are due to Indole production, arabinose, Malonate and Salicin utilization exhibited by bacterial No. 6 whereas bacterial No.1 showed fermentative properties for Mannitol, Raffinose and Sucrose. Bacterial isolates 1, 6, 9, 13 and 16 were ONPG and Nitrate reduction positive. Bacterial isolates 1, 6, 9, 13 and 16 showed positive results towards Citrate utilization and Mannose. Bacterial isolates 6, 9, 13 and 16 showed positive results towards Dextrose, Galatose and Melibiose. Bacterial isolate 16 showed positive results towards Cellbiose and Lactose. Bacterial isolates 9, 13 and 16 showed positive results towards Ornithine utilization and Voges proskauer's. Bacterial isolates 6 and 9 produces $\mathrm{H}_{2} \mathrm{~S}$. Bacterial isolate 7 showed positive results towards Inositol. Whereas bacterial isolate 1 has high fermentative capacity for Glucose, Mannitol, raffinose, Sucrose and Xylose.

\section{Phosphate Solubilization Potential of Native Microflora:}

Plate culture tests on Pikovaskya's media performed to observe the phosphate solubilizing ability of microbial isolates revealed that 10 bacterial and 8 fungal isolates exhibited the phosphate solubilization under in vitro condition. Solubilization capacity of these microbial isolates under solid culture conditions was also calculated in terms of solubilization index and solubilization efficiency. The highest solubilization index was observed in MLB-7 (2.72) and MLB-13 (2.75) (Table 1). Though, less comparatively, Colletotrichum gloeosporioides and Alternaria raphani showed good solubilization index. The solubilization potential calculated in terms of solubilization efficiency also confirms the good phosphate solubilization potential of MLB-7, MLB-9, Colletotrichum gloeosporioides and Alternaria raphani. The phosphate solubilization capacity of all these microbial strains were evaluated in submerged culture conditions also. Data presented in Table 1 expressed the change in $\mathrm{pH}$ of the culture media after growth and quality of phosphate release $(\mu \mathrm{g} / \mathrm{ml})$. In case of bacterial and fungal culture with and without TCP the $\mathrm{pH}$ of the culture filtrate was increased towards alkaline $\mathrm{pH}$. Very minor decline in the $\mathrm{pH}$ of some bacterial and fungal culture filtrate was observed except Aspergillus niger where $\mathrm{pH}$ was declined up to 2.5 and 3.07 in without and with TCP added media (Moderate negative correlation, $\mathrm{R}^{2}=0.5389, \mathrm{p}<0.01$ ). 
It is clearly evident that the most of the fungal culture are acid producers as they declined the $\mathrm{pH}$ of the normal medium after their growth in submerged liquid culture. Correlation between $\mathrm{pH}$ and phosphate soluilization is strongly and negatively concluded $\left(\mathrm{R}^{2}=0.5854, \mathrm{p}<0.01\right)$. Aspergillus niger solubilized $225.00 \pm 0.1011 \mu \mathrm{g} / \mathrm{ml}$ phosphate into the media. However, the solubilization potential of fungal culture in liquid submerged condition did not coincide with the plate culture tests. Solubilization efficiency is weakly and negatively correlated with phosphate content estimated $\left(\mathrm{R}^{2}=0.0977\right)$. On the other hand, bacterial isolates grown in submerged condition along with TCP did not decrease the $\mathrm{pH}$ even increase the final $\mathrm{pH}$ after $72 \mathrm{hrs}$ of incubation at $37{ }^{\circ} \mathrm{C}$. Though, all bacterial culture showed halo zone formation on PK plates, their submerged culture phosphate solubilization capabilities were poor as compared to fungal cultures. MLB-01 could be able to solubilize $59.00 \mu \mathrm{g} / \mathrm{ml}$ of Phosphate in the liquid media. However, all fungal and bacterial cultures were used as inoculants for the further pot experiment to evaluate their potential in plant growth and development of Madhuca latifolia in nursery condition.

\section{Evaluation of Phosphate Solubilizing Microbial Isolates under Pot Experiment}

Inoculation of different bacterial and fungal strains has resulted in different pattern of plant growth in non-transplanted plants as compared to uninoculated control. The data of shoot height measurements of seedlings in the nursery were presented in Table 2.1. It is evident that there are prominent and significant differences in seedlings height of control and those of inoculated seedlings. The application of non-sporulating dematiaceous form and Aspergillus terreus in fungal and MLB-1 and MLB-6 in bacterial inoculated plants showed maximum plant height as compared to other treatments $(\mathrm{p}<0.01)$. However, all inoculants exhibited growth promoting effect over control seedlings. The effect of another fungal application like Aspergillus niger is quite visible and significantly higher than the uninoculated control ( $\mathrm{p}<0.01)$.

Similarly, effect of microbial application on transplanted seedlings could also be observed. The morphological growth performance of experimental plants was presented in Table 2.2. The prominent and significant differences in seedling height of inoculated seedlings over control are evident $(\mathrm{p}<0.01)$. The application of non-sporulating dematiaceous form of fungus and Aspergillus terreus, MLB-1 and MLB-6 inoculated plants exhibited maximum plants height as compared to the other treatments $(\mathrm{p}<0.01)$. However, microbial inoculation showed growth promoting effect. The impact of application of Colletotrichum gloeosporioides and Aspergillus niger has also been quite visible and significantly higher as compared to uninoculated seedlings ( $\mathrm{p}$ $<0.01)$.

The inoculation of phosphate solubilizing bacteria and fungi also yielded good root growth in supplemented seedlings as compared to non-supplemented plants in non-transplanted plants (Table 2.1). Variable but significantly longer root had been observed in supplemented non-transplanted plants as compared to the non-supplemented control. MLB-1 has yielded longer roots followed by MLB-6 supplemented by bacteria that has given longer roots than uninoculated control. Similar, Aspergillus terreus has yielded longer roots followed by non-sporulating dematiaceous form in fungal supplemented that have given longer roots than uninoculated control ( $p<0.01)$. Significant difference was also observed for the number of leaves in fungal inoculated plants over control.

Data presented in Table 2.2 exhibited the effect of microbial application on transplanted plants inoculated transplanted seedling produced more vigorous roots as compared to uninoculated plants under these experimental sets. MLB-6 and MLB-1 showed higher root growth. Similarly, Aspergillus terreus and Aspergillus niger effected the root growth in positive manner. Inoculation of dematiaceous form of fungi and Aspergillus terreus exhibited the more no. of leaves as compared to control $(\mathrm{p}<0.01)$.

Mean Biomass (fresh and dry) measured after four months indicates the maximum increment in growth of plants inoculated with these bacteria and fungi in non-transplanted plants (Table 2.1). It is apparent that, in the term of biomass, the seedlings inoculated with different bacteria and fungi showed a higher production and superiority over control. On the other hand, most of the fungal strains exhibited higher fresh and dry biomass of shoot and root in supplemented non-transplanted 
seedlings as compared to the uninoculated control. It is evident that seedlings inoculated with dematiaceous fungi and Aspergillus terreus showed better shoot growth and highest biomass as compared to other treatments.

On other hand, transplanted seedlings under inoculated conditions showed maximum increment in growth and biomass as compared to control (Table 2.2). Evidently, inoculated and transplanted seedling showed superior biomass production in other bacterial and fungal than control. However, seedlings inoculated with MLB-6 and Aspergillus terreus exhibited better growth and higher biomass as compared to other treatments.

Relative growth rate (RGR) was also changed due to the enhancement, stem height and leaf area in supplemented seedlings in non-transplanted plants (Table 3.1). However, MLB-6 and nonsporulating dematiaceous form showed higher RGR in bacterial and fungal supplemented plants. Aspergillus terreus showed higher Net assimilation rate followed by non-sporulating dematiaceous form in fungal supplemented non-transplanted plants. MLB-6 showed higher Net assimilation rate followed by MLB-1 in bacterial supplemented non-transplanted plants. Data recorded on Root vigour index presented in Table 3.1 exhibited the superior response of MLB-1 and Aspergillus terreus over control and Shoot vigour index showed superior response of MLB-1 and Aspergillus terreus while MLB-6 and MLB-1 improved the Root vigour index under inoculated conditions.

The changes in plant growth of transplanted and inoculated seedlings also affected the physiological performance of plants in terms of Relative growth rate (Table 3.2). Higher RGR and Net assimilation rate were recorded on MLB-6 and non-sporulating dematiaceous form of fungus inoculated transplanted plants. Data recorded on Root vigour index and Shoot vigour index showed a variable response of MLB-1 and Aspergillus terreus which was superior over uninoculated control transplanted seedlings under experimental conditions.

The soil used in the experiment was red laterite soil having acidic $\mathrm{pH}$ and poor in mineral content. The texture was also rough, dry and porous nature. The physiochemical analysis of experimental soil represented in the Table 4.1 exhibited the decline in $\mathrm{pH}$ of soil used in inoculation experiment of bacterial and fungal inoculants. Among ten bacterial inoculations implemented during the pot experiment of non-transplanted Madhuca latifolia revealed the maximum decrease of $\mathrm{pH}$ in test soil inoculated with MLB-6. The soil $\mathrm{pH}$ recorded was acidic in nature and it was ranged to 4.805 to 5.460 . Among eight fungal inoculations implemented during the pot experiment revealed the maximum decrease of $\mathrm{pH}$ in test soil inoculated with Aspergillus nidulans. The soil $\mathrm{pH}$ recorded was acidic in nature and it was ranged to 4.940 to 5.165. All eighteen inoculated organism used in the experiment were organic carbon producers especially, Penicillium chermesinum followed by MLB-5. As far as the EC is concerned, all treated soil showed varied results ranged from 0.025 to $0.304 \mathrm{~d} \mathrm{~S} \mathrm{~m}^{-1}$.

Analysis of NPK of the soil collected from non-transplanted experimental Mahula plants rhizosphere showed significant differences as compared to the control. Almost all treatment exhibited the enhanced quality of $\mathrm{N}$ in the soil. All bacterial and fungal treated soil qualified for phosphorous showed more value as compared to the control except MLB-1. In similar way, Aspergillus terreus showed higher $\left(232.50 \mathrm{~kg} \mathrm{ha}^{-1}\right) \mathrm{P}$ in fungal treated soil. Other bacterial treatment showed enhanced level of $\mathrm{P}$ from control in the soil. As far as quantity of $\mathrm{K}$ is concerned, all treated soil has higher amount of $\mathrm{K}$ as comparision to the uninoculated control soil except MLB14 and Penicillium chermesinum.

Mineral analysis of rhizospheric soil of non-transplanted experimental plants showed significant change in NPK in most of the inoculated sets (Table 4.1). However, Aspergillus terreus performed better in improving soil mineral health as far as NPK level is concerned. Whereas other inoculants like MLB-1, MLB-17, MLB-16 and MLB-5 performed well in enhancing the mineral content of NPK in soil variants. However, the relative growth rate has positive but weak correlation with phosphate content of soil $\left(\mathrm{R}^{2}=0.788\right)$.

The physiological analysis of rhizospheric soil of transplanted and inoculated seedlings revealed the maximum decline in $\mathrm{pH}$ in test soil of Aspergillus terreus. Soil $\mathrm{pH}$ was acidic and $\mathrm{pH}$ was ranged 4.185 to 4.960 . The maximum OC was in fungal inoculated seedlings under 
transplantation conditions (Table 4.2). The higher amount of $\mathrm{N}$ content was recorded in MLB$1(591.50 \mathrm{Kg} / \mathrm{ha})$ and MLB-16 (700.50 Kg/ha) where as it was higher as compared to control in case of Aspergillus terreus (498.00 Kg/ha). In both the inoculation higher amount of $\mathrm{P}$ was also recorded in the soil of seedling rhizosphere inoculated with MLB-1 and Aspergillus terreus (i.e. $201.00 \pm 53.74$ and $220.50 \pm 50.21 \mathrm{Kg} / \mathrm{ha}$ ) respectively. This was weak positive correlation between RGR and phosphate content of the soil $\left(\mathrm{R}^{2}=0.0802\right)$. Inoculation of Aspergillus nidulans also effect the increment of phosphate in the soil $(221.50 \pm 21.92 \mathrm{Kg} / \mathrm{ha})$. In similar way, though the $\mathrm{N}$ and $\mathrm{K}$ content under this inoculation was not changed comparatively.

\section{Discussion}

As natural phenomenon, soil is composite system and endowed with variety of biological activity including mineral recycling. In similar way, the rhizosphere of Madhuca latifolia has also been found with a good number of bacteria and fungi. The rhizospheric soil was red laterite soil and with low phosphate content having possibilities of incidence of phosphate solubilizes positively (Sahoo et al. 2015). It is confirmed that the rhizosphere of the Madhuca latifolia is a good source of bacteria and fungi which are full of mineral solubilizing potential. Many of them were confirmed as good and potential Phosphate solubilizer under submerged liquid culture condition also. However, the fungi isolated from rhizospheric soil were more Phosphate solubilizing as compared to bacterial isolates. As an alternative to the chemical fertilizer either partially or fuel microbial inoculants have proven their role in growth enhancement in nursery conditions (Malik et al. 2013). It also helps in reducing the cost of chemical fertilizer and nourish the soil with ample supply of mineral elements (Mohan \& Rajendran 2014).To this context, the present experiment carried out on Madhuca latifolia under nursery conditions along with different treatments has also exhibited the promising and effective microbial potential in the growth improvement. Under experimental conditions MLB1 among bacterial inoculants and Aspergillus terreus among fungal inoculants were found to be very promising in increasing plant growth. However, MLB-6 bacteria and non-sporulating dematiaceous form of fungus were also prominent in improving length of shoot, length of roots and weight of roots of seedlings of Madhuca latifolia. Variations in plant growth due to fungal inoculation may be credited to their Phosphate solubilization potential and availability of Phosphate as well. In absence of fertilizer and the addition of bacterial and fungal inoculants, plants were established and survived up to 120 days after transplantation. This shows the positive role of bioinoculants towards plant seedling establishment and development.

Present studies also confirm the inoculation of Aspergillus terreus and MLB-1 in the rhizosphere of Madhuca latifolia is effective. Significant difference in morphological and physiological growth has been observed in the experimental plants. The present study has also been corroborated with the findings of the response of fungal inoculation on forest trees like Dalbergia sissoo and Acacia auriculiformis (Lalitha \& Santhaguru 2012, Dash et al. 2013). The factor responsible for phosphate solubilization may be organic acid as decline in $\mathrm{pH}$ of experimental rhizosphere soil, indicate the presence of these factors responsible for change in the $\mathrm{pH}$ of the medium.

It is clearly revealed in the present study that Aspergillus terreus and MLB-1 decline the $\mathrm{pH}$ of the soil and same had been found with low amount of ' $\mathrm{P}$ ' as compared to the uninoculated control soil $\left(\mathrm{R}^{2}=0.0702\right)$. The low amount of ' $\mathrm{P}$ ' content in the soil of experimental plant rhizosphere indicate the availability of the soluble Phosphorus and its subsequent utilization by the host plants, as the experimental plants of these sets were produced maximum plant height and biomass as compared to the control. The analysis of correlation between $\mathrm{pH}$ of soil and SVI of nontransplanted and transplanted experimental plants were weakly positive $\left(R^{2}=0.0054\right.$ and $R^{2}=$ 0.0519). All the experimental soil treated with the bacterial inoculation was observed as alkaline. It is also very clear that ' $\mathrm{P}$ ' content of the experimental soil was low as compared to control soil but not significantly at par with the fungal inoculated soil.

The major theme of the present study was based on the inoculation effect of bacterial and fungal inoculants on growth and development of Madhuca latifolia in non-transplanted and 
transplanted conditions. A positive effect of microbial application of phosphate solubilizing nature has clearly been evident in the present study. These organisms were isolated indigenously and proved the importance and usefulness of native microbes. This is a preliminary study, a vast experimentation with different combination of other useful inoculants fertilizer treatment, edaphic and environmental factors, seasonal variation are required to come out with biofertilizer consortium. However, the date recorded and observation made during this study is useful for the development of nursery with quality planting material of different forest trees.

Table 1 Phosphate solubilization properties of microbial isolates of Madhuca latifolia.

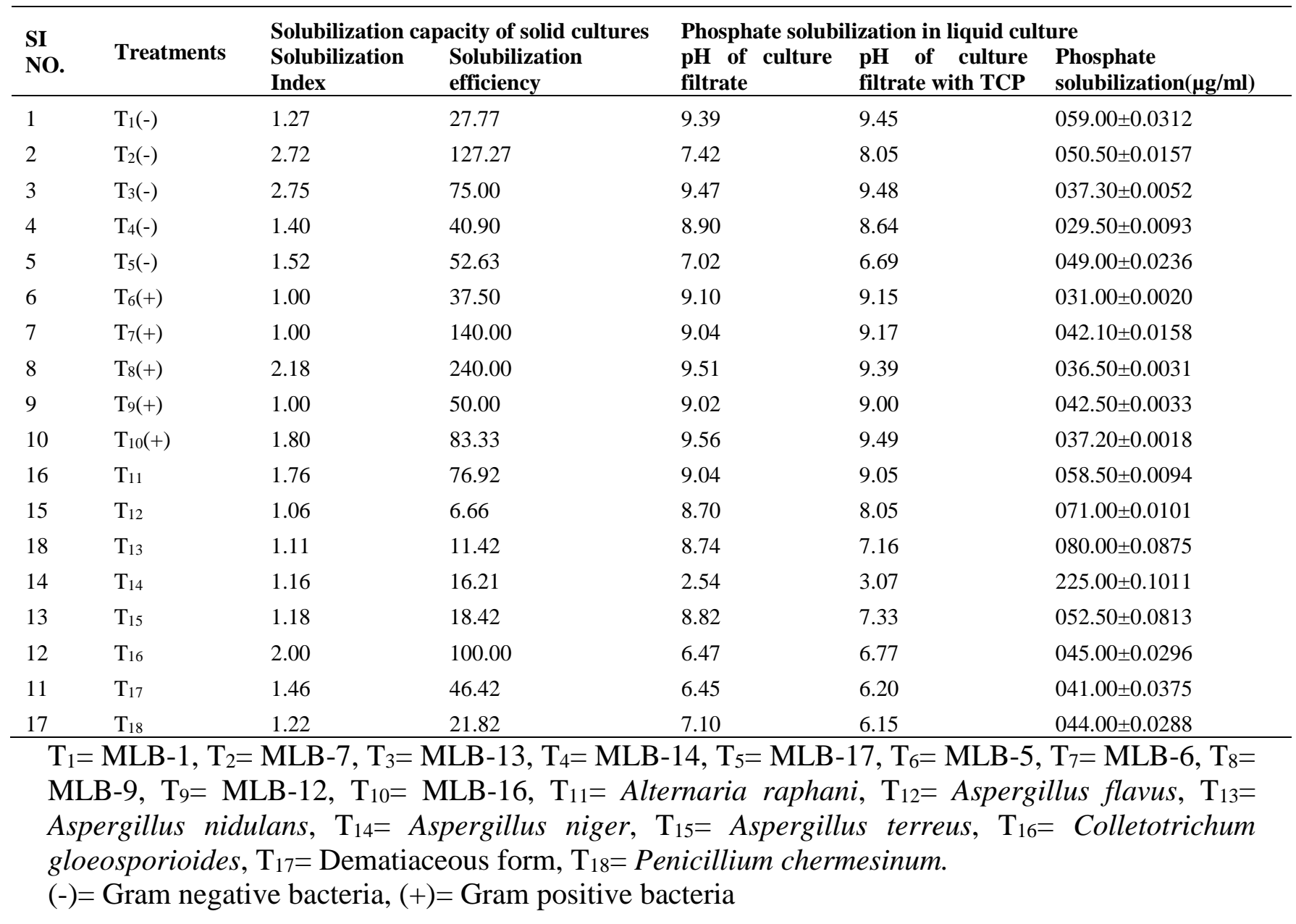


Table 2.1 Morphological growth performance of Madhuca latifolia under microbial inoculation and non-transplanted conditions.

\begin{tabular}{|c|c|c|c|c|c|c|c|c|}
\hline Treatment & $\begin{array}{l}\text { Length of } \\
\operatorname{shoot}(\mathrm{cms})\end{array}$ & $\begin{array}{l}\text { Fresh weight of } \\
\operatorname{shoot}(g)\end{array}$ & $\begin{array}{l}\text { Dried weight of } \\
\operatorname{shoot}(g)\end{array}$ & No. of leaves & $\begin{array}{l}\text { Length } \\
\operatorname{root}(\mathrm{cms}) \\
\end{array}$ & $\begin{array}{l}\text { Fresh weight of } \\
\operatorname{root}(g)\end{array}$ & $\begin{array}{l}\text { Dried weight of } \\
\operatorname{root}(g)\end{array}$ & Leaf $\operatorname{areas}\left(\mathrm{cm}^{2}\right)$ \\
\hline Control & $12.12 \pm 0.79$ & $11.87 \pm 0.99$ & $06.06 \pm 1.07$ & $04.8 \pm 0.84$ & $15.60 \pm 1.40$ & $15.45 \pm 3.55$ & $06.55 \pm 1.28$ & $1212.33 \pm 67.68$ \\
\hline $\mathrm{T}_{1}(-)$ & $23.54 \pm 1.31 * *$ & $14.25 \pm 0.83 *$ & $07.36 \pm 0.70$ & $07.0 \pm 0.71 *$ & $22.17 \pm 1.53 *$ & $18.37 \pm 1.91$ & $09.30 \pm 1.20$ & $1588.67 \pm 17.93 * *$ \\
\hline $\mathrm{T}_{2}(-)$ & $12.44 \pm 1.63$ & $11.09 \pm 0.50$ & $06.16 \pm 0.67$ & $07.0 \pm 0.71 *$ & $15.47 \pm 1.40$ & $16.78 \pm 1.60$ & $06.64 \pm 0.40$ & $1425.67 \pm 54.50 * *$ \\
\hline $\mathrm{T}_{3}(-)$ & $12.86 \pm 0.92$ & $10.54 \pm 1.67$ & $04.50 \pm 1.11$ & $05.6 \pm 1.82$ & $14.93 \pm 0.87$ & $14.89 \pm 1.59$ & $06.89 \pm 0.48$ & $1326.00 \pm 43.14$ \\
\hline $\mathrm{T}_{4}(-)$ & $14.40 \pm 0.89$ & $12.84 \pm 0.66$ & $06.02 \pm 0.60$ & $05.4 \pm 1.14$ & $14.10 \pm 0.79$ & $14.48 \pm 0.93$ & $06.96 \pm 0.46$ & $1385.33 \pm 51.25^{*}$ \\
\hline $\mathrm{T}_{5}(-)$ & $10.32 \pm 0.50$ & $11.03 \pm 0.54$ & $04.74 \pm 0.50$ & $06.2 \pm 1.64$ & $12.17 \pm 0.87$ & $10.74 \pm 0.96$ & $05.45 \pm 1.05$ & $1426.00 \pm 36.86^{* *}$ \\
\hline $\mathrm{T}_{6}(+)$ & $19.90 \pm 1.21$ & $12.26 \pm 1.03$ & $06.37 \pm 0.91$ & $07.2 \pm 1.92 *$ & $17.57 \pm 2.23$ & $16.52 \pm 1.16$ & $06.09 \pm 0.57$ & $1459.67 \pm 59.37 * *$ \\
\hline $\mathrm{T}_{7}(+)$ & $23.00 \pm 1.45^{* *}$ & $16.95 \pm 0.81 * *$ & $08.26 \pm 1.02 *$ & $06.2 \pm 0.84$ & $21.07 \pm 6.15$ & $21.01 \pm 1.37$ & $09.24 \pm 2.17$ & $1600.00 \pm 80.88^{* *}$ \\
\hline $\mathrm{T}_{8}(+)$ & $16.02 \pm 2.11$ & $10.84 \pm 1.13$ & $05.11 \pm 1.55$ & $06.6 \pm 2.07$ & $14.33 \pm 1.54$ & $16.03 \pm 1.93$ & $06.21 \pm 1.64$ & $1367.67 \pm 41.02 *$ \\
\hline $\mathrm{T}_{9}(+)$ & $14.62 \pm 0.82$ & $12.89 \pm 1.25$ & $06.14 \pm 1.17$ & $06.6 \pm 0.55$ & $15.23 \pm 2.40$ & $15.64 \pm 2.10$ & $06.94 \pm 0.42$ & $1378.33 \pm 49.22 *$ \\
\hline $\mathrm{T}_{10}(+)$ & $11.38 \pm 0.57$ & $11.92 \pm 0.57$ & $06.21 \pm 0.75$ & $06.8 \pm 0.84$ & $13.98 \pm 1.21$ & $12.52 \pm 0.85$ & $06.22 \pm 1.05$ & $1356.67 \pm 15.01 *$ \\
\hline $\mathrm{T}_{11}$ & $15.46 \pm 1.59$ & $18.32 \pm 2.37 * *$ & $08.55 \pm 0.61 *$ & $06.4 \pm 1.52$ & $17.57 \pm 1.40$ & $21.45 \pm 1.56^{*}$ & $09.38 \pm 0.55^{*}$ & $1342.00 \pm 12.00$ \\
\hline $\mathrm{T}_{12}$ & $12.48 \pm 0.58$ & $16.64 \pm 1.56 * *$ & $06.88 \pm 1.73$ & $08.0 \pm 1.22 *$ & $16.77 \pm 1.91$ & $18.03 \pm 0.31$ & $05.77 \pm 0.48$ & $1406.67 \pm 78.16^{*}$ \\
\hline $\mathrm{T}_{13}$ & $14.26 \pm 0.34$ & $13.38 \pm 0.83$ & $05.84 \pm 0.50$ & $07.4 \pm 1.14^{*}$ & $15.50 \pm 2.11$ & $19.21 \pm 1.38$ & $06.26 \pm 0.38$ & $1348.00 \pm 64.71$ \\
\hline $\mathrm{T}_{14}$ & $18.80 \pm 2.00$ & $17.34 \pm 1.90 * *$ & $07.92 \pm 0.54$ & $08.2 \pm 1.30^{*}$ & $18.13 \pm 1.01$ & $22.00 \pm 1.79 *$ & $08.00 \pm 0.40$ & $1478.33 \pm 77.88 * *$ \\
\hline $\mathrm{T}_{15}$ & $22.96 \pm 3.33 * *$ & $25.41 \pm 1.22 * *$ & $12.36 \pm 0.84 * *$ & $11.8 \pm 2.59 * *$ & $21.40 \pm 3.57 *$ & $31.33 \pm 1.06^{* *}$ & $13.26 \pm 1.27 * *$ & $1607.33 \pm 61.33^{* *}$ \\
\hline $\mathrm{T}_{16}$ & $16.48 \pm 1.63$ & $17.85 \pm 0.46^{* *}$ & $08.68 \pm 0.86^{* *}$ & $09.2 \pm 0.84 * *$ & $17.77 \pm 1.62$ & $19.94 \pm 1.22$ & $09.00 \pm 0.71$ & $1398.67 \pm 18.72 *$ \\
\hline $\mathrm{T}_{17}$ & $21.31 \pm 4.04 * *$ & $26.42 \pm 0.96^{* *}$ & $13.91 \pm 1.06^{* *}$ & $10.0 \pm 1.58 * *$ & $20.23 \pm 0.93 *$ & $30.27 \pm 1.25 * *$ & $12.50 \pm 0.71^{* *}$ & $1422.67 \pm 22.50 * *$ \\
\hline $\mathrm{T}_{18}$ & $15.26 \pm 0.76$ & $14.68 \pm 0.83^{*}$ & $07.55 \pm 1.11$ & $09.8 \pm 1.30 *$ & $15.43 \pm 0.93$ & $18.28 \pm 1.43$ & $07.04 \pm 0.69$ & $1359.00 \pm 73.26$ \\
\hline
\end{tabular}

$\pm=$ Standard deviation of five replicates

$* *=p<0.01$

$*=\mathrm{p}<0.05$

$\mathrm{T}_{1}=$ MLB-1, $\mathrm{T}_{2}=$ MLB-7, $\mathrm{T}_{3}=$ MLB-13, $\mathrm{T}_{4}=$ MLB-14, $\mathrm{T}_{5}=$ MLB-17, $\mathrm{T}_{6}=$ MLB-5, $\mathrm{T}_{7}=$ MLB- $6, \mathrm{~T}_{8}=$ MLB-9, $\mathrm{T}_{9}=$ MLB-12, $\mathrm{T}_{10}=$ MLB-16, $\mathrm{T}_{11}=$ Alternaria raphani, $\mathrm{T}_{12}=$ Aspergillus flavus, $\mathrm{T}_{13}=$ Aspergillus nidulans, $\mathrm{T}_{14}=$ Aspergillus niger, $\mathrm{T}_{15}=$ Aspergillus terreus, $\mathrm{T}_{16}=$ Colletotrichum gloeosporioides, $\mathrm{T}_{17}=$ Dematiaceous form, $\mathrm{T}_{18}=$ Penicillium chermesinum.

$(-)=$ Gram negative bacteria, $(+)=$ Gram positive bacteria 
Table 2.2 Morphological growth performance of Madhuca latifolia under microbial inoculation and transplanted conditions.

\begin{tabular}{|c|c|c|c|c|c|c|c|c|}
\hline Treatment & $\begin{array}{c}\text { Length of } \\
\operatorname{shoot}(\mathrm{cms})\end{array}$ & $\begin{array}{l}\text { Fresh weight of } \\
\operatorname{shoot}(g)\end{array}$ & $\begin{array}{l}\text { Dried weight of } \\
\operatorname{shoot}(g)\end{array}$ & No. of leaves & $\begin{array}{l}\text { Length of } \\
\operatorname{root}(\mathrm{cms})\end{array}$ & $\begin{array}{l}\text { Fresh weight of } \\
\operatorname{root}(\mathrm{g})\end{array}$ & $\begin{array}{l}\text { Dried weight of } \\
\operatorname{root}(\mathrm{g})\end{array}$ & Leaf $\operatorname{areas}\left(\mathrm{cm}^{2}\right)$ \\
\hline Control & $12.97 \pm 1.02$ & $07.89 \pm 0.18$ & $03.75 \pm 0.39$ & $04.6 \pm 1.14$ & $19.40 \pm 0.79$ & $14.89 \pm 2.31$ & $07.32 \pm 1.38$ & $1316.307 \pm 059.48$ \\
\hline $\mathrm{T}_{1}(-)$ & $24.09 \pm 1.98 * *$ & $14.91 \pm 0.69 * *$ & $07.68 \pm 0.73 * *$ & $06.4 \pm 1.14$ & $25.17 \pm 4.38 *$ & $22.97 \pm 4.43^{*}$ & $11.80 \pm 2.16^{*}$ & $1585.333 \pm 060.18^{* *}$ \\
\hline $\mathrm{T}_{2}(-)$ & $14.48 \pm 1.91$ & $11.07 \pm 0.62 * *$ & $06.66 \pm 1.69 * *$ & $06.6 \pm 1.14$ & $20.50 \pm 6.50$ & $18.64 \pm 4.55$ & $10.80 \pm 2.63$ & $1431.667 \pm 062.39$ \\
\hline $\mathrm{T}_{3}(-)$ & $12.23 \pm 1.12$ & $09.58 \pm 1.38$ & $04.82 \pm 0.94$ & $06.8 \pm 0.84$ & $16.53 \pm 1.40$ & $14.51 \pm 1.28$ & $08.77 \pm 0.96$ & $1415.667 \pm 016.01$ \\
\hline $\mathrm{T}_{4}(-)$ & $13.94 \pm 1.88$ & $12.45 \pm 0.77 *$ & $06.39 \pm 0.89 * *$ & $06.6 \pm 1.14$ & $16.53 \pm 4.21$ & $18.67 \pm 2.28$ & $09.76 \pm 0.97$ & $1390.667 \pm 024.44$ \\
\hline $\mathrm{T}_{5}(-)$ & $10.74 \pm 1.08$ & $09.79 \pm 0.85$ & $04.73 \pm 0.71$ & $06.0 \pm 2.00$ & $18.77 \pm 4.58$ & $17.80 \pm 0.86$ & $09.04 \pm 1.64$ & $1420.333 \pm 053.46$ \\
\hline $\mathrm{T}_{6}(+)$ & $19.40 \pm 1.12 * *$ & $11.08 \pm 1.30 *$ & $05.23 \pm 0.90 *$ & $07.4 \pm 2.07 *$ & $15.63 \pm 1.88$ & $20.74 \pm 6.05^{*}$ & $10.75 \pm 3.27 *$ & $1507.667 \pm 036.02 * *$ \\
\hline $\mathrm{T}_{7}(+)$ & $22.52 \pm 1.95 * *$ & $16.15 \pm 1.68 * *$ & $08.39 \pm 0.60 * *$ & $08.0 \pm 1.58 *$ & $26.27 \pm 1.81^{*}$ & $25.01 \pm 7.18 * *$ & $14.43 \pm 5.75^{* *}$ & $1637.667 \pm 040.67 * *$ \\
\hline $\mathrm{T}_{8}(+)$ & $14.29 \pm 2.60$ & $09.47 \pm 2.23$ & $04.83 \pm 0.86$ & $07.4 \pm 2.07 *$ & $20.27 \pm 2.11$ & $16.99 \pm 6.70$ & $08.98 \pm 4.10$ & $1337.333 \pm 063.14$ \\
\hline $\mathrm{T}_{9}(+)$ & $15.30 \pm 1.06$ & $12.81 \pm 3.40^{* *}$ & $04.53 \pm 0.72$ & $06.4 \pm 2.07$ & $17.40 \pm 3.26$ & $19.32 \pm 1.37$ & $10.53 \pm 0.50 *$ & $1384.333 \pm 041.04$ \\
\hline $\mathrm{T}_{10}(+)$ & $12.06 \pm 1.33$ & $12.11 \pm 0.67 *$ & $05.59 \pm 0.74$ & $07.0 \pm 2.00$ & $19.47 \pm 6.52$ & $18.97 \pm 2.39$ & $09.77 \pm 3.20$ & $1371.333 \pm 018.50$ \\
\hline $\mathrm{T}_{11}$ & $16.34 \pm 1.87$ & $19.52 \pm 2.27 * *$ & $09.77 \pm 1.45^{* *}$ & $08.0 \pm 1.23 *$ & $16.60 \pm 0.40$ & $21.46 \pm 2.96^{*}$ & $10.70 \pm 1.80$ & $1384.00 \pm 084.12$ \\
\hline $\mathrm{T}_{12}$ & $13.50 \pm 1.50$ & $16.83 \pm 2.91 * *$ & $08.09 \pm 2.13^{* *}$ & $06.4 \pm 1.52$ & $13.20 \pm 1.11$ & $20.36 \pm 1.50 *$ & $9.92 \pm 0.84$ & $1380.00 \pm 036.39$ \\
\hline $\mathrm{T}_{13}$ & $15.76 \pm 2.45$ & $16.18 \pm 2.10^{* *}$ & $08.00 \pm 1.56^{* *}$ & $06.2 \pm 2.17$ & $16.03 \pm 1.01$ & $18.75 \pm 0.55$ & $08.86 \pm 0.49$ & $1337.33 \pm 048.39$ \\
\hline $\mathrm{T}_{14}$ & $19.50 \pm 3.84 * *$ & $18.35 \pm 1.81^{* *}$ & $09.07 \pm 2.28 * *$ & $09.6 \pm 2.30 * *$ & $18.83 \pm 2.99$ & $22.19 \pm 1.35^{*}$ & $12.08 \pm 0.65^{* *}$ & $1408.00 \pm 065.94$ \\
\hline $\mathrm{T}_{15}$ & $23.26 \pm 2.40 * *$ & $24.55 \pm 3.49 * *$ & $13.40 \pm 2.34 * *$ & $13.0 \pm 1.58 * *$ & $20.73 \pm 1.91$ & $26.59 \pm 3.93 * *$ & $14.17 \pm 3.54 * *$ & $1565.00 \pm 077.38$ \\
\hline $\mathrm{T}_{16}$ & $16.06 \pm 1.50$ & $16.77 \pm 2.55^{* *}$ & $08.51 \pm 1.31 * *$ & $07.0 \pm 1.58$ & $14.93 \pm 1.34$ & $20.38 \pm 1.07$ & $9.82 \pm 2.31$ & $1439.00 \pm 051.03$ \\
\hline $\mathrm{T}_{17}$ & $21.14 \pm 2.91 * *$ & $23.54 \pm 3.71 * *$ & $12.19 \pm 3.19 * *$ & $10.4 \pm 2.70 * *$ & $17.77 \pm 1.88$ & $24.20 \pm 2.44 * *$ & $12.34 \pm 2.49 * *$ & $1511.00 \pm 039.66^{* *}$ \\
\hline $\mathrm{T}_{18}$ & $15.06 \pm 3.16$ & $15.62 \pm 0.80^{* *}$ & $06.81 \pm 1.34 *$ & $07.4 \pm 1.82$ & $14.53 \pm 1.47$ & $19.29 \pm 1.58$ & $09.55 \pm 0.98$ & $1379.00 \pm 032.14$ \\
\hline
\end{tabular}

$\pm=$ Standard deviation of five replicates

$* *=p<0.01$

$*=p<0.05$ 
Table 3.1 Physiological growth performance of Madhuca latifolia under microbial inoculation and non-transplanted conditions.

\begin{tabular}{|c|c|c|c|c|c|c|}
\hline Treatment & Shoot vigour index & Root vigour index & Net assimilation rate & Leaf area ratio & Relative growth rate & Quality index \\
\hline Control & $1212.0 \pm 078.18$ & $1560.00 \pm 140.00$ & $0.88 \pm 0.27$ & $0.72 \pm 0.08$ & $0.08 \pm 0.0200$ & $0.68 \pm 0.36$ \\
\hline $\mathrm{T}_{1}(-)$ & $2354.2 \pm 131.33$ & $2216.67 \pm 152.75$ & $1.67 \pm 0.16$ & $0.76 \pm 0.05$ & $0.11 \pm 0.0110$ & $2.00 \pm 0.27$ \\
\hline $\mathrm{T}_{2}(-)$ & $1244.0 \pm 163.49$ & $1546.67 \pm 140.48$ & $1.02 \pm 0.11$ & $0.84 \pm 0.05$ & $0.08 \pm 0.0080$ & $0.56 \pm 0.16$ \\
\hline $\mathrm{T}_{3}(-)$ & $1286.0 \pm 092.36$ & $1493.33 \pm 087.37$ & $0.72 \pm 0.02$ & $0.89 \pm 0.03$ & $0.06 \pm 0.0003$ & $0.59 \pm 0.22$ \\
\hline $\mathrm{T}_{4}(-)$ & $1440.0 \pm 089.16$ & $1410.00 \pm 079.37$ & $1.02 \pm 0.12$ & $0.81 \pm 0.06$ & $0.08 \pm 0.0100$ & $0.52 \pm 0.16$ \\
\hline $\mathrm{T}_{5}(-)$ & $1031.8 \pm 049.61$ & $1216.67 \pm 087.37$ & $0.65 \pm 0.10$ & $1.02 \pm 0.10$ & $0.05 \pm 0.0090$ & $0.85 \pm 0.26$ \\
\hline $\mathrm{T}_{6}(+)$ & $1990.0 \pm 120.83$ & $1756.67 \pm 222.79$ & $1.01 \pm 0.17$ & $0.87 \pm 0.02$ & $0.07 \pm 0.0090$ & $0.52 \pm 0.08$ \\
\hline $\mathrm{T}_{7}(+)$ & $2300.0 \pm 145.09$ & $2106.67 \pm 614.93$ & $1.74 \pm 0.35$ & $0.75 \pm 0.13$ & $0.12 \pm 0.0270$ & $0.89 \pm 0.15$ \\
\hline $\mathrm{T}_{8}(+)$ & $1602.0 \pm 211.12$ & $1433.33 \pm 153.73$ & $0.84 \pm 0.40$ & $0.89 \pm 0.23$ & $0.07 \pm 0.0310$ & $0.44 \pm 0.17$ \\
\hline $\mathrm{T}_{9}(+)$ & $1462.0 \pm 082.28$ & $1523.33 \pm 240.07$ & $1.02 \pm 0.20$ & $0.80 \pm 0.04$ & $0.08 \pm 0.0130$ & $0.52 \pm 0.17$ \\
\hline $\mathrm{T}_{10}(+)$ & $1138.0 \pm 057.18$ & $1398.00 \pm 121.21$ & $0.88 \pm 0.13$ & $0.84 \pm 0.06$ & $0.07 \pm 0.0100$ & $0.61 \pm 0.20$ \\
\hline $\mathrm{T}_{11}$ & $1546.0 \pm 159.00$ & $1756.67 \pm 140.12$ & $1.54 \pm 0.08$ & $0.61 \pm 0.03$ & $0.12 \pm 0.0070$ & $0.53 \pm 0.09$ \\
\hline $\mathrm{T}_{12}$ & $1248.0 \pm 058.05$ & $1676.67 \pm 191.40$ & $1.12 \pm 0.09$ & $0.78 \pm 0.03$ & $0.08 \pm 0.0020$ & $0.61 \pm 0.19$ \\
\hline $\mathrm{T}_{13}$ & $1426.0 \pm 033.62$ & $1550.00 \pm 210.71$ & $0.87 \pm 0.09$ & $0.83 \pm 0.03$ & $0.07 \pm 0.0050$ & $0.38 \pm 0.07$ \\
\hline $\mathrm{T}_{14}$ & $1880.0 \pm 199.87$ & $1813.33 \pm 100.66$ & $1.37 \pm 0.14$ & $0.89 \pm 0.06$ & $0.10 \pm 0.0100$ & $0.62 \pm 0.10$ \\
\hline $\mathrm{T}_{15}$ & $2296.0 \pm 332.91$ & $2140.00 \pm 356.79$ & $2.83 \pm 0.34$ & $0.67 \pm 0.03$ & $0.19 \pm 0.0160$ & $0.89 \pm 0.14$ \\
\hline $\mathrm{T}_{16}$ & $1648.0 \pm 163.00$ & $1776.67 \pm 161.66$ & $1.54 \pm 0.19$ & $0.65 \pm 0.04$ & $0.12 \pm 0.0130$ & $0.6 \pm 0.12$ \\
\hline $\mathrm{T}_{17}$ & $2130.6 \pm 403.74$ & $2023.33 \pm 092.92$ & $2.57 \pm 0.09$ & $0.48 \pm 0.02$ & $0.19 \pm 0.0070$ & $1.05 \pm 0.23$ \\
\hline $\mathrm{T}_{18}$ & $1526.0 \pm 076.03$ & $1543.33 \pm 092.92$ & $1.24 \pm 0.11$ & $0.70 \pm 0.07$ & $0.10 \pm 0.0110$ & $0.46 \pm 0.04$ \\
\hline
\end{tabular}

$\pm=$ Standard deviation of five replicates

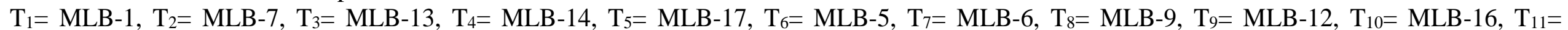

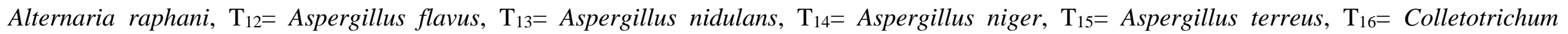
gloeosporioides, $\mathrm{T}_{17}=$ Dematiaceous form, $\mathrm{T}_{18}=$ Penicillium chermesinum .

$(-)=$ Gram negative bacteria, $(+)=$ Gram positive bacteria 
Table 3.2 Physiological growth performance of Madhuca latifolia under microbial inoculation and transplanted conditions.

\begin{tabular}{|c|c|c|c|c|c|c|}
\hline Treatment & Shoot vigour index & Root vigour index & Net assimilation rate & Leaf area ratio & Relative growth rate & Quality index \\
\hline Control & $1297.4 \pm 102.44$ & $1940.00 \pm 0789.37$ & $0.73 \pm 0.22$ & $0.87 \pm 0.05$ & $0.06 \pm 0.02$ & $0.66 \pm 0.37$ \\
\hline $\mathrm{T}_{1}(-)$ & $2409.0 \pm 197.88$ & $2516.67 \pm 438.44$ & $2.06 \pm 0.41$ & $0.67 \pm 0.06$ & $0.15 \pm 0.03$ & $2.63 \pm 0.58$ \\
\hline $\mathrm{T}_{2}(-)$ & $1448.0 \pm 190.97$ & $2050.00 \pm 650.00$ & $1.59 \pm 0.44$ & $0.67 \pm 0.09$ & $0.13 \pm 0.03$ & $1.25 \pm 0.28$ \\
\hline $\mathrm{T}_{3}(-)$ & $1223.0 \pm 111.56$ & $1653.33 \pm 140.48$ & $1.07 \pm 0.19$ & $0.81 \pm 0.08$ & $0.09 \pm 0.02$ & $0.74 \pm 0.39$ \\
\hline $\mathrm{T}_{4}(-)$ & $1394.0 \pm 187.96$ & $1653.33 \pm 421.47$ & $1.41 \pm 0.12$ & $0.68 \pm 0.05$ & $0.12 \pm 0.01$ & $1.18 \pm 0.49$ \\
\hline $\mathrm{T}_{5}(-)$ & $1074.0 \pm 108.31$ & $1876.67 \pm 457.86$ & $1.12 \pm 0.28$ & $0.80 \pm 0.10$ & $0.09 \pm 0.02$ & $1.29 \pm 0.52$ \\
\hline $\mathrm{T}_{6}(+)$ & $1940.0 \pm 112.47$ & $1563.33 \pm 187.71$ & $1.51 \pm 0.37$ & $0.75 \pm 0.14$ & $0.11 \pm 0.03$ & $0.84 \pm 0.28$ \\
\hline $\mathrm{T}_{7}(+)$ & $2252.0 \pm 195.12$ & $2626.67 \pm 181.48$ & $2.56 \pm 0.91$ & $0.62 \pm 0.12$ & $0.18 \pm 0.06$ & $1.45 \pm 0.57$ \\
\hline $\mathrm{T}_{8}(+)$ & $1412.8 \pm 273.22$ & $2026.67 \pm 211.27$ & $1.11 \pm 0.43$ & $0.75 \pm 0.14$ & $0.09 \pm 0.04$ & $0.61 \pm 0.40$ \\
\hline $\mathrm{T}_{9}(+)$ & $1530.4 \pm 106.47$ & $1740.00 \pm 326.04$ & $1.27 \pm 0.12$ & $0.71 \pm 0.07$ & $0.10 \pm 0.01$ & $0.79 \pm 0.44$ \\
\hline $\mathrm{T}_{10}(+)$ & $1206.2 \pm 132.99$ & $1946.67 \pm 652.48$ & $1.31 \pm 0.39$ & $0.70 \pm 0.12$ & $0.11 \pm 0.03$ & $1.26 \pm 0.27$ \\
\hline $\mathrm{T}_{11}$ & $1634.0 \pm 186.50$ & $1660.00 \pm 040.00$ & $1.85 \pm 0.37$ & $0.57 \pm 0.10$ & $0.15 \pm 0.03$ & $0.67 \pm 0.19$ \\
\hline $\mathrm{T}_{12}$ & $1350.0 \pm 150.00$ & $1320.00 \pm 111.36$ & $1.59 \pm 0.27$ & $0.63 \pm 0.07$ & $0.13 \pm 0.02$ & $0.67 \pm 0.04$ \\
\hline $\mathrm{T}_{13}$ & $1576.0 \pm 245.21$ & $1603.33 \pm 101.16$ & $1.31 \pm 0.26$ & $0.67 \pm 0.05$ & $0.11 \pm 0.02$ & $0.51 \pm 0.17$ \\
\hline $\mathrm{T}_{14}$ & $1950.0 \pm 384.06$ & $1883.33 \pm 299.39$ & $2.11 \pm 0.24$ & $0.54 \pm 0.01$ & $0.17 \pm 0.01$ & $1.05 \pm 0.05$ \\
\hline $\mathrm{T}_{15}$ & $2326.0 \pm 240.38$ & $2073.33 \pm 191.40$ & $2.99 \pm 0.92$ & $0.52 \pm 0.12$ & $0.22 \pm 0.06$ & $1.98 \pm 0.66$ \\
\hline $\mathrm{T}_{16}$ & $1606.0 \pm 150.27$ & $1493.33 \pm 134.29$ & $1.66 \pm 0.38$ & $0.66 \pm 0.10$ & $0.13 \pm 0.03$ & $0.64 \pm 0.15$ \\
\hline $\mathrm{T}_{17}$ & $2114.0 \pm 290.82$ & $1776.67 \pm 188.24$ & $2.29 \pm 0.56$ & $0.58 \pm 0.10$ & $0.17 \pm 0.05$ & $1.76 \pm 0.18$ \\
\hline $\mathrm{T}_{18}$ & $1506.0 \pm 316.04$ & $1453.33 \pm 147.42$ & $1.36 \pm 0.11$ & $0.68 \pm 0.03$ & $0.11 \pm 0.01$ & $0.48 \pm 0.09$ \\
\hline
\end{tabular}

$\pm=$ Standard deviation of five replicates

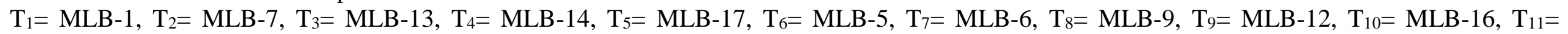

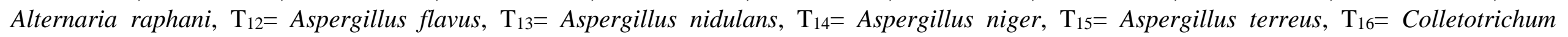
gloeosporioides, $\mathrm{T}_{17}=$ Dematiaceous form, $\mathrm{T}_{18}=$ Penicillium chermesinum .

$(-)=$ Gram negative bacteria, $(+)=$ Gram positive bacteria 
Table 4.1 Analysis of soil sample of experimental non-transplanted Madhuca latifolia.

\begin{tabular}{|c|c|c|c|c|c|c|}
\hline Treatment & pH & EC(dSm-1) & OC(g/kg soil) & Avl.N(kg/ha) & Avl.P(kg/ha) & Avl.K(kg/ha) \\
\hline Control & $4.930 \pm 0.21$ & $0.014 \pm 0.009$ & $04.125 \pm 2.609$ & $166.00 \pm 024.04$ & $008.70 \pm 03.25$ & $0442.5 \pm 465.98$ \\
\hline $\mathrm{T}_{1}(-)$ & $4.920 \pm 0.17$ & $0.068 \pm 0.014$ & $08.950 \pm 2.475$ & $383.50 \pm 126.57$ & $087.00 \pm 56.57$ & $0634.0 \pm 005.66$ \\
\hline $\mathrm{T}_{2}(-)$ & $5.020 \pm 0.10$ & $0.033 \pm 0.001$ & $07.730 \pm 2.234$ & $315.50 \pm 204.35$ & $063.00 \pm 45.26$ & $0527.0 \pm 272.94$ \\
\hline $\mathrm{T}_{3}(-)$ & $5.065 \pm 0.06$ & $0.066 \pm 0.052$ & $10.000 \pm 0.001$ & $268.50 \pm 007.78$ & $095.50 \pm 20.51$ & $0450.5 \pm 328.81$ \\
\hline $\mathrm{T}_{4}(-)$ & $5.095 \pm 0.02$ & $0.090 \pm 0.026$ & $08.960 \pm 0.255$ & $274.00 \pm 080.61$ & $105.50 \pm 41.72$ & $0253.5 \pm 215.67$ \\
\hline $\mathrm{T}_{5}(-)$ & $5.090 \pm 0.41$ & $0.121 \pm 0.025$ & $08.255 \pm 0.742$ & $382.50 \pm 146.37$ & $037.50 \pm 12.02$ & $0731.0 \pm 127.28$ \\
\hline $\mathrm{T}_{6}(+)$ & $5.035 \pm 0.15$ & $0.052 \pm 0.033$ & $11.430 \pm 4.483$ & $263.00 \pm 032.53$ & $137.00 \pm 25.46$ & $1287.0 \pm 731.15$ \\
\hline $\mathrm{T}_{7}(+)$ & $4.805 \pm 0.19$ & $0.090 \pm 0.082$ & $08.435 \pm 1.987$ & $256.50 \pm 071.42$ & $074.00 \pm 46.67$ & $0529.5 \pm 294.87$ \\
\hline $\mathrm{T}_{8}(+)$ & $4.935 \pm 0.11$ & $0.050 \pm 0.029$ & $07.645 \pm 1.365$ & $285.50 \pm 031.82$ & $096.00 \pm 28.28$ & $0473.0 \pm 049.50$ \\
\hline $\mathrm{T}_{9}(+)$ & $5.165 \pm 0.04$ & $0.025 \pm 0.013$ & $06.675 \pm 0.502$ & $223.00 \pm 056.57$ & $039.00 \pm 16.97$ & $0348.5 \pm 105.36$ \\
\hline $\mathrm{T}_{10}(+)$ & $5.065 \pm 0.04$ & $0.053 \pm 0.037$ & $07.995 \pm 0.870$ & $217.00 \pm 065.05$ & $132.00 \pm 66.47$ & $0623.0 \pm 206.48$ \\
\hline $\mathrm{T}_{11}$ & $5.170 \pm 0.06$ & $0.210 \pm 0.058$ & $03.955 \pm 2.397$ & $262.00 \pm 045.26$ & $102.50 \pm 13.44$ & $0519.5 \pm 013.44$ \\
\hline $\mathrm{T}_{12}$ & $5.045 \pm 0.02$ & $0.162 \pm 0.013$ & $10.930 \pm 2.927$ & $236.50 \pm 081.32$ & $142.50 \pm 06.36$ & $0504.0 \pm 107.48$ \\
\hline $\mathrm{T}_{13}$ & $5.250 \pm 0.07$ & $0.304 \pm 0.106$ & $08.100 \pm 1.061$ & $243.00 \pm 00.001$ & $145.50 \pm 86.97$ & $0708.5 \pm 243.95$ \\
\hline $\mathrm{T}_{14}$ & $5.350 \pm 0.09$ & $0.148 \pm 0.006$ & $09.225 \pm 0.530$ & $224.00 \pm 045.26$ & $065.00 \pm 52.33$ & $0639.5 \pm 207.18$ \\
\hline $\mathrm{T}_{15}$ & $5.460 \pm 0.11$ & $0.103 \pm 0.037$ & $11.150 \pm 0.919$ & $337.00 \pm 089.10$ & $232.50 \pm 61.52$ & $0755.5 \pm 010.61$ \\
\hline $\mathrm{T}_{16}$ & $5.590 \pm 0.19$ & $0.030 \pm 0.013$ & $08.605 \pm 0.247$ & $245.50 \pm 088.39$ & $075.50 \pm 17.68$ & $0479.5 \pm 061.52$ \\
\hline $\mathrm{T}_{17}$ & $5.030 \pm 0.06$ & $0.051 \pm 0.004$ & $07.900 \pm 0.990$ & $257.00 \pm 008.49$ & $081.00 \pm 09.89$ & $0690.0 \pm 226.27$ \\
\hline $\mathrm{T}_{18}$ & $4.940 \pm 0.13$ & $0.156 \pm 0.006$ & $11.680 \pm 10.92$ & $281.00 \pm 018.39$ & $100.00 \pm 35.36$ & $0202.0 \pm 227.69$ \\
\hline
\end{tabular}

$\pm=$ Standard deviation of five replicates

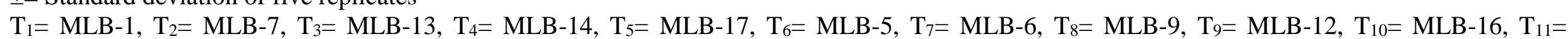

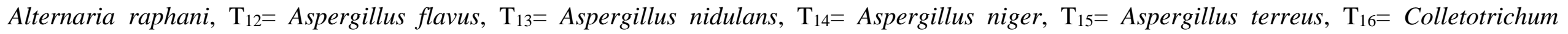
gloeosporioides, $\mathrm{T}_{17}=$ Dematiaceous form, $\mathrm{T}_{18}=$ Penicillium chermesinum .

$(-)=$ Gram negative bacteria, $(+)=$ Gram positive bacteria 
Table 4.2 Analysis of soil sample of experimental transplanted Madhuca latifolia.

\begin{tabular}{|c|c|c|c|c|c|c|}
\hline Treatment & pH & EC(dSm-1) & OC(g/kg soil $)$ & Avl.N(kg/ha) & Avl.P(kg/ha) & Avl.K(kg/ha) \\
\hline Control & $4.465 \pm 0.346$ & $0.095 \pm 0.076$ & $8.15 \pm 0.636$ & $311.50 \pm 021.920$ & $192.00 \pm 193.75$ & $539.00 \pm 445.48$ \\
\hline $\mathrm{T}_{1}(-)$ & $4.130 \pm 0.057$ & $0.140 \pm 0.022$ & $7.70 \pm 1.273$ & $591.50 \pm 352.846$ & $201.00 \pm 053.74$ & $367.00 \pm 011.31$ \\
\hline $\mathrm{T}_{2}(-)$ & $4.645 \pm 0.247$ & $0.069 \pm 0.016$ & $1.40 \pm 0.141$ & $202.50 \pm 021.920$ & $090.50 \pm 031.82$ & $277.00 \pm 008.49$ \\
\hline $\mathrm{T}_{3}(-)$ & $4.300 \pm 0.198$ & $0.087 \pm 0.023$ & $1.55 \pm 0.707$ & $288.00 \pm 022.627$ & $088.00 \pm 113.14$ & $279.00 \pm 214.96$ \\
\hline $\mathrm{T}_{4}(-)$ & $4.475 \pm 0.346$ & $0.081 \pm 0.004$ & $2.60 \pm 1.556$ & $439.00 \pm 083.439$ & $154.50 \pm 120.92$ & $508.50 \pm 389.62$ \\
\hline $\mathrm{T}_{5}(-)$ & $4.020 \pm 0.042$ & $0.090 \pm 0.010$ & $5.75 \pm 1.202$ & $265.00 \pm 043.841$ & $162.00 \pm 008.49$ & $282.50 \pm 036.06$ \\
\hline $\mathrm{T}_{6}(+)$ & $4.245 \pm 0.021$ & $0.051 \pm 0.006$ & $2.65 \pm 0.636$ & $296.00 \pm 043.841$ & $023.00 \pm 021.21$ & $083.00 \pm 032.53$ \\
\hline $\mathrm{T}_{7}(+)$ & $4.540 \pm 0.453$ & $0.096 \pm 0.020$ & $2.20 \pm 1.273$ & $358.00 \pm 066.468$ & $154.00 \pm 076.37$ & $271.50 \pm 028.99$ \\
\hline $\mathrm{T}_{8}(+)$ & $4.350 \pm 0.198$ & $0.086 \pm 0.001$ & $1.45 \pm 0.212$ & $311.50 \pm 021.920$ & $136.00 \pm 059.39$ & $340.50 \pm 043.13$ \\
\hline $\mathrm{T}_{9}(+)$ & $4.355 \pm 0.092$ & $0.055 \pm 0.052$ & $0.80 \pm 0.141$ & $280.50 \pm 021.920$ & $123.00 \pm 060.81$ & $308.50 \pm 054.45$ \\
\hline $\mathrm{T}_{10}(+)$ & $4.055 \pm 0.021$ & $0.115 \pm 0.011$ & $1.70 \pm 0.141$ & $700.50 \pm 021.920$ & $125.50 \pm 051.62$ & $286.00 \pm 025.46$ \\
\hline $\mathrm{T}_{11}$ & $4.355 \pm 0.007$ & $0.078 \pm 0.001$ & $13.45 \pm 2.758$ & $210.50 \pm 033.234$ & $199.50 \pm 020.51$ & $309.50 \pm 047.38$ \\
\hline $\mathrm{T}_{12}$ & $4.240 \pm 0.141$ & $0.113 \pm 0.046$ & $12.55 \pm 1.909$ & $376.00 \pm 041.021$ & $183.00 \pm 052.33$ & $323.50 \pm 071.42$ \\
\hline $\mathrm{T}_{13}$ & $4.485 \pm 0.049$ & $0.079 \pm 0.001$ & $11.55 \pm 3.889$ & $257.00 \pm 011.314$ & $221.50 \pm 021.92$ & $582.00 \pm 035.36$ \\
\hline $\mathrm{T}_{14}$ & $4.915 \pm 0.106$ & $0.078 \pm 0.012$ & $13.00 \pm 0.566$ & $311.50 \pm 088.388$ & $177.50 \pm 058.69$ & $519.50 \pm 020.51$ \\
\hline $\mathrm{T}_{15}$ & $4.185 \pm 0.262$ & $0.105 \pm 0.045$ & $8.90 \pm 1.414$ & $498.00 \pm 154.149$ & $220.50 \pm 050.21$ & $575.50 \pm 034.65$ \\
\hline $\mathrm{T}_{16}$ & $4.620 \pm 0.255$ & $0.061 \pm 0.000$ & $6.05 \pm 6.435$ & $358.00 \pm 022.627$ & $141.00 \pm 029.69$ & $424.00 \pm 083.44$ \\
\hline $\mathrm{T}_{17}$ & $4.960 \pm 0.410$ & $0.061 \pm 0.011$ & $7.15 \pm 0.778$ & $304.00 \pm 098.995$ & $117.00 \pm 059.39$ & $252.00 \pm 059.39$ \\
\hline $\mathrm{T}_{18}$ & $4.640 \pm 0.113$ & $0.084 \pm 0.004$ & $11.90 \pm 3.818$ & $350.50 \pm 164.756$ & $175.00 \pm 024.04$ & $395.50 \pm 019.09$ \\
\hline
\end{tabular}

$\pm=$ Standard deviation of five replicates

$\mathrm{T}_{1}=$ MLB-1, $\mathrm{T}_{2}=$ MLB-7, $\mathrm{T}_{3}=$ MLB-13, $\mathrm{T}_{4}=$ MLB-14, $\mathrm{T}_{5}=$ MLB-17, $\mathrm{T}_{6}=$ MLB-5, $\mathrm{T}_{7}=$ MLB-6, $\mathrm{T}_{8}=$ MLB-9, $\mathrm{T}_{9}=\mathrm{MLB}_{-12}, \mathrm{~T}_{10}=\mathrm{MLB}_{1}-16, \mathrm{~T}_{11}=$ Alternaria raphani, $\mathrm{T}_{12}=$ Aspergillus flavus, $\mathrm{T}_{13}=$ Aspergillus nidulans, $\mathrm{T}_{14}=$ Aspergillus niger, $\mathrm{T}_{15}=$ Aspergillus terreus, $\mathrm{T}_{16}=$ Colletotrichum gloeosporioides, $\mathrm{T}_{17}=$ Dematiaceous form, $\mathrm{T}_{18}=$ Penicillium chermesinum.

$(-)=$ Gram negative bacteria, $(+)=$ Gram positive bacteria 


\section{Acknowledgements}

The financial assistance obtained from the Forest and Environment dept., Govt. of Odisha (State plan 2016-17) is gratefully acknowledged.

\section{References}

Barnett HL, Hunter BB. 1972. - Identification of Fungi, Illustrated Genera of Imperfect Fungi.

Bhardwaj D, Ansari MW, Sahoo RK, Tuteja N. 2014 - Biofertilizers function as key player in sustainable agriculture by improving soil fertilizers, plant tolerance and crop productivity. Microbial Cell Factories 13, 66.

Dash S, Mohapatra AK, Gupta N. 2013 - Growth response of Dalbergia sissoo Roxb. to mineral solubilizing bacteria and fungi in nursery conditions. International Society for Tropical Ecology 54, 109-115.

Elias F, Woyessa D, Muleta D. 2016 - Phosphate Solubilization potential of Rhizosphere fungi isolated from plants in Jimma Zone, Southwest Ethiopia. International Journal of Microbiology, 11.

Karpagam T, Nagalahskmi PK. 2014 - Isolation and characterization of phosphate solubilizing microbes from agricultural soil. International Journal of Current Microbiology and Applied Sciences 3, 601-614.

Lalitha S, Santhaguru K. 2012 - Improving soil physical properties and effect on tree legume seedlings growth under barren soil. Agricultural Science Research Journal 2, 126-130

Malik A, Shazia L, Fayaz AL, Aflaq H. 2013 - Field performance of blue pine (Pinus wallichiana) seedlings inoculated with selected species of bio-inoculants under nursery condition. International Journal of Pharma and Biosciences 4, 632-64.

Mohan E, Rajendran K. 2014 - Effect of plant growth promoting Microorganism on quality seedling production of Feronia elephatum (Corr.) in semi-arid region of Sourthern India. International Journal of Current Microbiology and Applied Sciences 3, 103-116.

Nagamani A, Kunwar IK, Manoharachary C. 2013. - Handbook of Soil Fungi, I.K. International, Pvt. Ltd. S-25 Green Park Extension, New Delhi.

Puhan S, Vedaraman N, Rambrahamam BV, Nagarajan G. 2005 - Mahua (Madhuca indica) seed oil: A source of renewable energy in India. Journal of Scientific and Industrial Research 64, 890-896.

Sahoo HR, Sahoo M, Baboo M, Gupta N. 2015 - Effect of red laterite soil and vermicompost on growth and development of chilli and brinjal grown under polypot conditions. Tropical Plant Research 2, 172-174.

Sharma SB, Sayyed RZ, Trivedi MH, Gobi TA. 2013 - Phosphate solubilizing microbes: sustainable approach for managing phosphorus deficiency in agricultural soils. Spinger Plus $2,587$.

Tandon HLS. 1999 - Methods of analysis of soils, plants, waters and fertilisers (Publ. Fertiliser development and consultation organization, New Delhi, India), pp. 13-35.

Wyszkowska J, Borowik A, Kucharski J, Bacmaga M et al. 2013 - The effect of organic fertilizers on the biochemical properties of soil contaminated with zinc. Plant Soil Environment 59, 500-504.

Zhu F, Qu L, Hong X, Sun X. 2011 - Isolation and characterization of a phosphate-solubilizing alophilic bacterium Kushneria sp. YCWA18 from Daqiao Saltern on the coast of yellow sea of China. Evidence-Based Complimentary and Alternative Medicine 2011, 6. 